\title{
Pharmacological and Pharmaceutical Technological Overview for Seborrheic Dermatitis: A Review About Topical Application and New Approaches
}

\author{
A. Alper Öztürk1* ${ }^{*}$ Evrim Yenilmez ${ }^{1}$ \\ 1 Anadolu University, Faculty of Pharmacy, Department of Pharmaceutical Technology, Eskişehir, Turkey.
}

\begin{abstract}
Seborrheic dermatitis (SD) is a skin disease with chronic recurrent erythematous plaques in areas where sebaceous glands are intense. The etiology of SD remains unknown, although many factors such as lipophilic yeasts of the Malassezia genus, hormones, genetic, environmental and general health factors have been shown to be causative. SD is affecting body parts involving rich sebaceous glands such as head and skin. Treatment options include application of anti-inflammatory, antifungal, keratolytic, and sebosupressive agents. The SD causes are briefly mentioned in this review. Then, detailed information was given about the medicines used in SD treatment. The most important element of this article is to be used in SD treatment; new approaches such as new formulations, new active substances and narrow band UV rays have been mentioned. Finally, some examples of the Pharmacist's role in SD treatment in general are given.
\end{abstract}

Keywords: Seborrheic dermatitis; Formulation; Topical applications

\section{INTRODUCTION}

Seborrheic dermatitis (SD) is an amateur skin disease with chronic recurrent erythematous plaques in areas where sebaceous glands are intense. ${ }^{1}$ The causes of SD are unknown, but many people with the condition tend to have excessive yeast in their skin in affected areas. Having certain medical conditions can raise the risk for $\mathrm{SD}$. Other conditions that may put someone at risk for SD are: chronic acne, alcoholism or excessive alcohol use, depression, eating disorders, psoriasis and rosacea. ${ }^{1,2,3}$

SD is a chronic inflammatory skin disorder affecting the head, skin, and body. Typically, SD is characterized by dandruff or flaking skin (on the scalp, hair, 
beard, mustache or eyebrows), greasy skin patches (on the scalp, face, nose, eyelids, ears, chest, armpits, groin and under the breasts), inflamed, itchy, reddish skin. ${ }^{2}$ In adolescents and adults, SD usually occurs as dandruff, head desquamation and erythema in the nasolabial fold which develops in the newborn period, suggesting that it may be a response to maternal hormone stimulation. SD affects mostly post-pubertal people, but this condition mentioned above also affects a high percentage of infants (around 70 percent) and sometimes children. In fact, cradle cap is one type of seborrheic dermatitis, which affects a baby's scalp. Seborrheic dermatitis can also develop in the diaper area of infants and is sometimes mistaken for diaper rash. In infants, the condition generally resolves by age 3 or 4 months. But children with untreated food allergies can sometimes continue to show symptoms for years. Another time period when seborrheic dermatitis tends to develop is during puberty, when hormone shifts can affect the glands of the skin and oil production. Dermatitis prevalence increases again in adults over the age of 50.4,5,6,7 Research as additional evidence of hormonal activity has shown that SD emerges in response to androgen stimulation. ${ }^{2,3}$ Currently, SDis treated with agents such as antifungal shampoo, topical corticosteroids, topical antifungals, topical calcineurin inhibitors.

In this study, firstly, the causes and properties of SD were briefly examined. The drug groups, topical systems and new aproaches such silver nanoparticles, nanocrystals, new therapeutic agents, narrow-band ultraviolet as used in the treatment are then explained in detail.

\section{Causes of SD}

SD is caused by seborrhea, pathologically excessive sebum secretion and infection-inflammation observed afterwards. Lipophilic yeasts, genetic factors, environmental and general health factors contribute to this disorder. ${ }^{4}$

\section{Fungal causes}

Although the cause of SD has not yet been fully proven, Malassezia that a lipophilic yeast form, may be an inflammatory reaction originating from the spread of yeast. The main species found on the head skin; $M$. globosa, M. restricta, $M$. obtusa, M. sloojjiae, M. sympodialis, M.jurjur, and M. pachydermatis (the last occurs only on animals). M. globosa and M. restricta are thought to be the species most commonly associated with SD, although $\mathrm{M}$. jurjur and other species have also been implicated. Some studies have found high numbers of Malassezia yeasts on the scalp of persons with $\mathrm{SD}$, but others have found no difference in the density of these yeasts between the skin of persons with SD and that of persons without it. Differing sampling methods may contribute to these contra- 
dictory findings. Malassezia exist not only on the skin surface, but also within the layers of the stratum corneum, and a true count would require examining the full thickness of the skin squama. Support for the role of Malassezia in SD comes from studies demonstrating that use of various antifungal treatments results in reduction of Malassezia, which is accompanied by improvement in symptoms. ${ }^{1-5}$

The toxic substances produced by these yeasts irritate and inflammate the skin. It has been observed that patients with SD have a low resistance to this yeast. However, the proportion of skin affected by the colony may be lower than unaffected skin. ${ }^{3,45}$

Thus, a definitive understanding of the pathophysiology of SD awaits further research, but the role of Malassezia yeasts as causative or contributing agents appears to be well established.

\section{Other causes}

Seborrheic dermatitis commonly occurs among patients with other health conditions that affect their immune systems and raise inflammation. Genetic and environmental factors and other comorbid diseases may lead to the development of SD, which may accelerate the formation of seborrhoeic dermatitis. SD affects only 3 percent of the population. However, this rate can be up to $85 \%$ in people with acquired immunodeficiency syndrome (AIDS). The mechanism of HIV (human immunodeficiency virus) infection promoting a typical and explosive seborrhoeic dermatitis and other common inflammatory skin disorders is not fully known; but effective factors such as CD4-positive T-lymphocyte count, $P$. ovale concentration and nutritional factors are still being investigated. ${ }^{4}$ Persons with central nervous system disorders (Parkinson's disease, cranial nerve paralysis, large body paralysis) tend to develop SD, in which the disease is more extensive and treatment resistance is observed. In these patients with SD, it has been suggested that the amount of sebum increased due to inactivity resulting in SD. The increased amount of sebaceum supports the development of P. ovale, the cause of SD. Researchers also notes that risk for SD also increases if person taking drugs such as interferon, lithium and psoralen. Even in those who do not have other serious health problems, the risk factors for SD include: stress, trauma, low exposure to sunlight and hormonal changes such as menopause and pregnancy. ${ }^{2,4,6}$

\section{Clinical Signs and Diagnosis of SD}

SD is most commonly found in the face and / or head skin and is associated with an unidentified erythematous patch associated with a fine-grained (pitriaziform) scale; one of which is more locating area. Other areas commonly affected 
by SD; forehead parts of the forehead, anterior hairline area, glabella areas of the forehead, nasal folds, melolabial folds, ears (external ducts, anterior auricular region, retroauricular region), sternum-centered chest area and the genital area. ${ }^{4,6,7}$ As mentioned earlier, SD usually has symmetrical distribution in these areas. 4

One of the features of SD is the blemish on the bran with a thin, powder-white scale. Many patients complain of the scalp itching with dandruff, and because they think that the scale arises from dry skin, they decrease the frequency of shampooing, which allows further scale accumulation. Inflammation then occurs, and their symptoms worsen..$^{4,5,6}$

More severe SD is characterized by erythematous plaques frequently associated with powdery or greasy scale in the scalp, behind the ears and elsewhere in the distribution described above. Besides an itchy scalp, patients may complain of a burning sensation in facial areas affected by seborrhea. Seborrhea frequently becomes apparent when men grow mustaches or beards and disappears when the facial hair is removed. If left untreated, the scale may become thick, yellow and greasy and, occasionally, secondary bacterial infection may occur. ${ }^{4}$

$\mathrm{SD}$ is more common in men than in women, probably because sebaceous gland activity is under androgen control. Seborrhea usually first appears in persons in their teens and twenties and generally follows a waxing/waning course throughout adulthood. 4

The differential diagnosis of SD should include psoriasis, rosacea, Demodex dermatitis, atopic eczema, pityriasis versicolor, contact dermatitis, and tinea infections. SD may also resemble Langerhans cell histiocytosis or secondary syphilis. The diagnosis is usually clinical, but candidiasis, tinea infection, and Demodex dermatitis may be ruled out with a negative potassium hydroxide test. It should be kept in mind that SD may be accompanied by other dermatological disorders. ${ }^{4}$

Care should be taken to differentiate SD from psoriasis vulgaris. Early SD has a spongiform appearance that distinguishes it from psoriasis, but in later stages these conditions are more difficult to tell apart. Some patients present with sebopsoriasis, which includes features of both disease states.2 Lesions on the elbows or knees and nail pitting suggest psoriasis, which may spare the face. ${ }^{4}$

Finally; the most common signs and symptoms of SD are:1,4,8,9

- Scaly patches and dandruff forming on the scalp. Dandruff is usually "stubborn" and doesn't respond well even to over-the-counter products like dandruff shampoos or oily treatments. Sometimes, rash-like lesions form on the scalp 
that can range from mildly itchy to brownish crusts and cause the skin to stick to the hair.

- Red skin that's sensitive and very dry. Irritated SDcan cause very dry skin to become yellow or pink in certain areas.

- Extra dryness and flaking in areas of the skin that fold or that are usually oily, including the "T-zone" of the face (the area covering the nose, chin and forehead), upper chest and back.

- Skin peeling called erythema, which sometimes appears as macules (a discolored patch of skin) or plaques with dry white or moist oily scales. Even when skin peels, papules or pustules are not very common.

- It's possible for secondary bacterial infections to occur if bacteria proliferate inside dry patches or openings of the skin.

\section{Treatment of SD}

Hygiene plays a key role in controlling SD. Frequent cleaning with soap will remove the fat in the affected areas and help to heal SD. Patients should be informed that hygiene conditions are very important for a good life. The so-called 'open-air reaction' observed especially during the summer will increase seborrhea and precautions must be taken to prevent sun damage. ${ }^{3,4,7}$

There are anti-inflammatory agents (topical steroids) and antifungal agents (selenium sulfide, zinc pyrite, azole agents, sodium sulfacetamide, topical terbinafine etc.) that reduce lipophilic yeast colonization as a pharmacological treatment option for SD. In severe disease states, keratolytic agents such as salicylic acid and tar preparations may be used to remove intense scaling followed by treatment with topical steroids. ${ }^{4,8,9}$

Sebosupressive agents such as isotretinoin can be used as a last resort in the problem of resistant SD to reduce sebaceous gland activity. ${ }^{3}$

Drugs used in the treatment of SD are summarized in next section. This information was supported by RxMediaPharma $\AA$ and the literature. RxMediaPharma $®$ is a comprehensive drug information resource. The goal is to support doctors, pharmacists and other health professionals in their current knowledge, to inform them about new developments and to ensure that information is delivered quickly. ${ }^{59}$

\section{Drugs for SD}

Beclamethazone dipropionate: It is used topically in the treatment of certain skin diseases with severe inflammation, such as eczema, which does not 
respond to weaker corticosteroids. There are pomade, cream and lotion forms. ${ }^{10}$ Betamethasone: It is anti-inflammatory and antipruritic medicine. It is used in the treatment of dermatoses that respond to topical corticosteroid therapy. ${ }^{11}$

Betamethasone valerate: It is used against the inflammation seen in dermatoses that respond to corticosteroid treatment. It has anti-inflammatory and antipruritic effect. ${ }^{12}$

Cetrimide: This drug is a quaternary ammonium derivative and antiseptic. Shampoos containing 1 to $3 \%$ of cetirimide are used against perspiration in case of SD. ${ }^{13}$

Clobetazol propionate: This drug is an effective topically applied synthetic fluorocorticosteroid. It is used in the treatment of inflammatory and pulmonary symptoms caused by moderate to severe dermatoses and psoriasis that respond to corticosteroids. ${ }^{14}$

Clobetazon butyrate: This drug is an effective topically applied synthetic fluorocorticosteroid. It is an anti-inflammatory corticosteroid that is used in inflammatory conditions not related to infection, especially in the treatment of eczematous disorders. It is used in all kinds of eczema and dermatitis cases. More powerful corticosteroid drugs are used for treatment of idiopathic remedies. There are $0.05 \%$ creams and ointments. ${ }^{15}$

Dexamethasone, Dexamethasone sodium phosphate: They have antiinflammatory effect. When given in pharmacological doses, they prevent inflammation and immune responses. ${ }^{16,17}$

Dezonide: It has anti-inflammatory effect. Dezonide (prednasinolone) is a prednisolone derivative corticosteroid used topically to treat various skin diseases. Acute and chronic eczema responding to topical corticosteroid therapy; neurodermatitis; contact, chronic and SD; dermatitis; chronic lichen simplex; hypertrophic lichen planus; anogenital and senile pruritus; psoriasis and other similar cases. ${ }^{18}$

Diflucortolone valerate: It is a powerful corticosteroid used topically for the treatment of various skin diseases. It is used in the treatment of certain skin diseases with severe and resistant inflammation, such as stubborn eczema, which does not respond to less powerful corticosteroids. It is also indicated in cases such as dermatomycosis due to yeast and yeast-like fungi causing SD, tinea and candidiasis. ${ }^{19,20}$

Flucortolone hexanoate, Flucortolone pivalate: These drugs have antiinflammatory effect. They are used in contact dermatitis, SD, various eczema 
types, neurodermatitis, psoriasis, lichen ruber planus, atopic dermatitis, burns and insect infestations. It is used in cream and pomade forms. ${ }^{21,22}$

Flumethazone pivalate: This drug has anti-Inflammatory effect. It is used to treat various inflammatory skin diseases such as various eczema that respond to topical corticosteroid treatment. Cream, pomade, lotion forms are available. ${ }^{23}$

Flucinolone acetonide: This drug has anti-Inflammatory effect. It is a topically applied chlorinated corticosteroid. Corticosteroids are used in the treatment of susceptible dermatoses and psoriasis. There are forms of cream, pomade, topical solution, shampoo and topical oily solution. ${ }^{24}$

Flusinonid: When this drug administered topically, the inflammation caused by acute and chronic dermatoses is abolished by anti-inflammatory, antipruritic and vasoconstrictor effects specific to topical corticosteroids. It is used in the symptomatic treatment of skin diseases characterized by inflammation and / or pruritis, such as SD, atopic dermatitis and psoriasis which respond to corticosteroid treatment in the form of cream, gel, solution and lotion. ${ }^{25}$

Fluticasone propionate: This drug has anti-inflammatory, antipruritic, vasoconstrictor effects. It is a synthetic corticosteroid with medium strength. It is used against inflammatory and pruritic symptoms of dermatosis and psoriasis which respond to topical corticosteroids. The antiflammatory activity of topical fluticasone is 13 times that of triamnisolone acetonide, 9 times that of flucinolone acetonide, 3 times that of betamethasone valerate and 2 times that of beclomethasone propionate. ${ }^{26}$

Halometasone: It is a potent corticosteroid administered topically. This drug has anti-inflammatory, antiallergic, vasoconstrictor and antiproliferative effects. It is usually used against inflammatory skin diseases of various types and origins. These include inflammatory skin diseases such as non-infected SD, contact dermatitis, atopic dermatitis, localized neurodermatitis (lichen simplex cronicus), numeral eczema and psoriasis vulgaris, which respond to corticosteroid therapy. For this purpose, creams and ointments containing 0.05\% halomatazon are used. ${ }^{27}$

Halsinoid: The topically used steroid is a highly fluorescent synthetic corticosteroid. Corticosteroid-sensitive dermatosis is used in the treatment of inflammatory and pruritic symptoms of psoriasis. Anti-inflammatory, antipruritic and vasoconstrictor effect. inflammation and pruritus associated with acute and chronic dermatoses. ${ }^{28}$

Hydrocortisone, Hydrocortisone acetate: It is a steroid hormone that secretes adrenal cortex. The preparations are in the form of natural hormones 
as well as their derivatives. Like topical corticosteroids, hydrocortisone has antiinflammatory, antipruritic and vasoconstrictor effects. Cream, cream, lotion-like preparations are available. ${ }^{29,30}$

Hydrocortisone butyrate: It has anti-inflammatory, antiproliferative, vasoconstrictor, antiallergic and antipruritic effect. There are various pharmaceutical forms which are prepared according to the type and degree of the skin disease and which have the effect of helping the skin. ${ }^{31}$

Itraconazole: It is an antifungal medication that is similar to ketoconazole in the oral route. The effectiveness of the treatment of dermatophyte infections in the skin that do not respond to topical treatment is being investigated..$^{32}$

Juniper tar (cade oil): This antiseptic drug is used as an ointment directly on the skin. It is also used externally for the treatment of eczema and psoriasis. This drug is used to treat seborrhea, eczema, psoriasis, dandruff, scalp and pruritus. This drug enters the combination of shampoos prepared for this therapeutic purpose. ${ }^{33}$

Ketoconazole: It is an antifungal drug included in the imidazole group. Ketoconazole is the only drug that is capable of inhibiting the synthesis of adrenal steroids at higher doses than the doses required for antifungal activity. Oral tablet, topical cream (2\%) and shampoo (2\%) are available. There is also a $1 \%$ shampoo for use against the head. ${ }^{34}$

Methylprednisolone, Methylprednisolone acetate: These drugs are an anti-inflammatory and immunosuppressive agent. Pharmacology is the natural hormone that prevents or suppresses inflammation and immune responses when given in doses. ${ }^{35}$

Mometasone furoate: This drug is a moderate synthetic corticosteroid with anti-inflammatory, antipruritic and vasoconstrictor properties. It is used topically against dermatoses that respond to corticosteroids and inflammatory and pruritic symptoms due to psoriasis. ${ }^{36}$

Prithion zinc: This medicine is used in the treatment of simple dandruff, dry and oily type of SD. For this purpose $2 \%$ concentration is applied. It goes into the combination of the shampoos used against the head. The mechanism of action has not been fully elucidated. According to one opinion, it has bacteriostatic and fungicidal action. According to another opinion, it shows cytostatic effect on decrease of turnover rate in epidermal cells. ${ }^{37}$

Prednicarbat: This drug is a synthetic topical corticosteroid with no halogen and is moderately effective. This drug is used to treat the inflammatory and 
pruritic symptoms of dermatosis and psoriasis that respond to corticosteroid therapy. ${ }^{38}$

Prednisolone, Prednisolone acetate: These drugs are anti-inflammatory and immunosuppressive synthetic glucocorticoid. ${ }^{39,40}$

Salicylic acid: It's a kerolytic drug. It is used in the treatment of diseases such as dandruff, SD, ichthyosis, psoriasis and acne with hyperkeratotic and deep scaling. Solutions and pomades are used for this purpose. Salicylic acid reduces desquamation and is slightly fungicidal..$^{41,42}$

Selenium sulfide: It's an antifungal and antiseborrheic agent. Shampoos are used in the treatment of dandruff, SD and tinea versicolor. Antiseborrheic effect is due to cytostatic effect on cells in epidermis and follicular epithelium. Used topically. $1 \%$ shampoos for dandruff treatment, 2. 5\% shampoo or lotions for SD treatment.7,9

\section{Topical pharmaceutical forms for the treatment of SD}

With the exception of severe SD treatment, it can be treated with pharmaceutical forms such as cream, lotion, ointment, pomade, shampoo, solution, suspension in the scalp, face, beard zone and body in the treatment of SD. These pharmaceutical forms and examples will be examined separately in the next section.

\section{Cream}

Topical drug delivery can be defined as the administration of a drug containing the formulation to the skin. It can be used primarily to treat cutaneous manifestations of a universal disease such as cutaneous diseases such as acne or psoriasis and for many purposes. The main purpose of this transmission is to limit the pharmacological or other effect of the drug to the skin surface or deeper skin layers. $43,44,45$ Creams, which are a semi-solid emulsion formula, are applied to skin or mucous membranes. Oil-in-water (w/o) emulsion type creams are less oily and well spread than ointments. Water-in-oil (o/w) emulsion type creams are easily applied to the skin and are easily removed with water. ${ }^{44}$ Antifungal, corticosteroid or combination cream formulations used in the treatment of SD are presented in Table 1. 
Table 1. Topical cream preparations currently used in Turkey for SD.

\begin{tabular}{|c|c|}
\hline $\begin{array}{l}\text { The name of the preparation, } \\
\text { pharmaceutical form, amount }\end{array}$ & Active ingredients and ratio \\
\hline Beklazon, cream, $30 \mathrm{~g}$ tube/box & Beclamethazone dipropionate $0.025 \%$ \\
\hline Betnovate, cream $30 \mathrm{~g}$ tube/box & Betamethasone valerate $0.1 \%$ \\
\hline Betnovate-C, cream, $30 \mathrm{~g}$ tube/box & $\begin{array}{c}\text { Betamethasone valerate } 0.1 \% \\
\text { Clioquinol \%3 }\end{array}$ \\
\hline Codermo, cream, $30 \mathrm{~g}$ tube/box & Mometasone furoate $0.1 \%$ \\
\hline Dermatop, cream, $30 \mathrm{~g}$ tube/box & Prednikarbat $0.25 \%$ \\
\hline Dermovate, cream, $50 \mathrm{~g}$ tube/box & Clobetazol propionate $0.05 \%$ \\
\hline Diprolene, cream, $15 \mathrm{~g}$ tube/box & Betamethasone dipropionate $0.05 \%$ \\
\hline Eumovate, cream, $50 \mathrm{~g}$ tube/box & Clobetazon butyrate $0.05 \%$ \\
\hline Fucicort, cream, $30 \mathrm{~g}$ tube/box & $\begin{array}{c}\text { Fusidic acid } 2 \% \\
\text { Betamethasone valerate } 0.1 \%\end{array}$ \\
\hline Hexacorton, cream, $30 \mathrm{~g}$ tube/box & Prednisolone acetate $0.5 \%$ \\
\hline Hipokort, cream, $30 \mathrm{~g}$ tube/box & Hydrocortisone acetate $0.5 \%$ \\
\hline Impetex, cream,10 g tube/box & $\begin{array}{c}\text { Diflucortolone valerate } \% 0.1 \text {, } \\
\text { Chlorquinaldol } \% 1\end{array}$ \\
\hline Ketoderm, cream, $30 \mathrm{~g}$ tube/box & Ketoconazole $2 \%$ \\
\hline $\begin{array}{l}\text { Locacortene-Vioforme, cream, } \\
15 \mathrm{~g} \text { tube/box-30 g tube/box }\end{array}$ & $\begin{array}{c}\text { Flumetazone pivalate } 0.02 \% \\
\text { Clioquinol } 3 \%\end{array}$ \\
\hline Locoid, cream, $30 \mathrm{~g}$ tube/box & Hydrocortisone 17-Butyrate $0.1 \%$ \\
\hline Locoid, lipocream, $30 \mathrm{~g}$, tube/box & Hydrocortisone 17-Butyrate $0.1 \%$ \\
\hline M-Furo, cream, $30 \mathrm{~g}$ tube/box & Mometasone furoate $0.1 \%$ \\
\hline Nerisona C, cream, $15 \mathrm{~g}$ tube/box & $\begin{array}{c}\text { Diflukortolone valerate } 0.1 \% \text {, } \\
\text { Chlorquinaldol } \% 1\end{array}$ \\
\hline Nizoral, cream, $30 \mathrm{~g}$ tube/box & Ketoconazole $2 \%$ \\
\hline Prednol, cream, $30 \mathrm{~g}$ tube/box & Prednasinolon $0.125 \%$ \\
\hline Prednol-A, cream, $30 \mathrm{~g}$ tube/box & $\begin{array}{l}\text { Prednasinolon } 0.125 \% \text {, } \\
\text { lodochlorhydroscine } 3 \%\end{array}$ \\
\hline Sicorten, cream, 30g tube/box & Halomethasone $0.05 \%$ \\
\hline Tetemex, cream, $10 \mathrm{~g}$ tube/box & Diflukortolone valerate $0.1 \%$ \\
\hline Ultralan, cream, $20 \mathrm{~g}$ tube/box & $\begin{array}{l}\text { Flucortolon caproate } 0.25 \% \\
\text { Flucontholon } 0.25 \%\end{array}$ \\
\hline Ureacort, cream, $30 \mathrm{~g}$ tube/box & $\begin{array}{c}\text { Urea } 5 \% \\
\text { Hydrocortisone acetate } 0.05 \%\end{array}$ \\
\hline Hydrocortisone acetate $0.05 \%$ & $\begin{array}{c}\text { Urea } 10 \% \\
\text { Hydrocortisone acetate } 0.05 \%\end{array}$ \\
\hline
\end{tabular}

* Information was obtained from the RxMediaPharma $®$ interactive drug information resource. ${ }^{59}$ 


\section{Lotion}

Lotion is a low to moderately viscous topical preparation for application to unbroken skin. Lotions are applied to the skin with bare hands, with a clean cloth, cotton or gauze, and provide cooling effects on the skin by solvent evaporation. ${ }^{44}$ Lotions are liquid preparations in which a finely divided insoluble drug is suspended or dispersed. They are easily applied to the hair planting areas and spread easily. ${ }^{46}$ Corticosteroid or combination lotion formulations used in the treatment of SD are presented in Table 2.

Table 2. Topical lotion preparations currently used in Turkey for SD.

\begin{tabular}{|c|c|}
\hline $\begin{array}{c}\text { The name of the preparation, } \\
\text { pharmaceutical form, amount }\end{array}$ & Active ingredients and ratio \\
\hline Beklazon, lotion, $50 \mathrm{~mL}$ bottle/box & Beclamethazone dipropionate $0.025 \%$ \\
\hline Betasalic, lotion, $50 \mathrm{~mL}$ bottle/box & $\begin{array}{c}\text { Salicylic acid } 2 \% \\
\text { Beclamethazone dipropionate } 0.05 \%\end{array}$ \\
\hline Betnovate, lotion $20 \mathrm{~mL}$ bottle/box & Betamethasone valerate $0.1 \%$ \\
\hline Betnovate, hair lotion, $30 \mathrm{~mL}$ bottle/box & Betamethasone valerate $0.1 \%$ \\
\hline Codermo, lotion, $30 \mathrm{~mL}$ bottle/box & Mometasone furoate $0.1 \%$ \\
\hline Dermovat, Hair lotion, $25 \mathrm{~mL}$ bottle/box & Clobetazol propionate $0.05 \%$ \\
\hline Elocon, lotion, $30 \mathrm{~mL}$ bottle/box & Mometasone furoate $0.1 \%$ \\
\hline M-Furo, lotion, $30 \mathrm{~mL}$ bottle/box & Mometasone furoate $0.1 \%$ \\
\hline Psoderm, hair lotion, $25 \mathrm{~mL}$ bottle/box & Clobetazole propionate $0.05 \%$ \\
\hline
\end{tabular}

* Information was obtained from the RxMediaPharma ${ }^{\circledR}$ interactive drug information resource. ${ }^{59}$

\section{Ointment}

Ointments are biphasic devices believed to be occlusive, which prevents transcutaneous water loss and water trapping on the skin surface..$^{46}$ It is a greasy semisolid preparation of dissolved or dispersed drug. Ointment bases influence topical drug bioavailability due to their occlusive properties of the stratum corneum, which enhances the flux of drug across the skin and they affect drug dissolution and drug partitioning within or from the ointment to the skin, respectively ${ }^{44}$. Antifungal, corticosteroid or combination ointment formulations used in the treatment of SD are presented in Table 3. 
Table 3. Topical oinment preparations currently used in Turkey for SD

\begin{tabular}{|c|c|}
\hline $\begin{array}{l}\text { The name of the preparation, } \\
\text { pharmaceutical form, amount }\end{array}$ & Active ingredients and ratio \\
\hline Betasalic, ointment, $30 \mathrm{~g}$ tube/box & $\begin{array}{c}\text { Salicylic acid 3\% } \\
\text { Beclamethazone dipropionate } 0.05 \%\end{array}$ \\
\hline Betnovate, ointment $30 \mathrm{~g}$ tube/box & Betamethasone valerate $0.1 \%$ \\
\hline Betnovate-C, ointment, $30 \mathrm{~g}$ tube/box & $\begin{array}{c}\text { Betamethasone valerate } 0.1 \% \\
\text { Clioquinol \%3 }\end{array}$ \\
\hline Codermo, ointment, $30 \mathrm{~g}$ tube/box & Mometasone furoate $0.1 \%$ \\
\hline Cutivate, ointment, $30 \mathrm{~g}$ tube/box & Fluticasone propionate $0.005 \%$ \\
\hline Dermatop, ointment, $30 \mathrm{~g}$ tube/box & Prednikarbat $0.25 \%$ \\
\hline Dermovate, ointment, $50 \mathrm{~g}$ tube/box & Clobetazol propionate $0.05 \%$ \\
\hline Eumovate, ointment, $50 \mathrm{~g}$ tube/box & Clobetazon butyrate $0.05 \%$ \\
\hline Heksa, ointment, $15 \mathrm{~g}$ tube/box & $\begin{array}{c}\text { Polymyxin B sulfate } 0.1 \% \\
\text { 0xytetracycline hydrochloride } 3 \%\end{array}$ \\
\hline Ketoral, ointment, $40 \mathrm{~g}$ tube/box & Ketoconazole $2 \%$ \\
\hline Locasalene, ointment, $30 \mathrm{~g}$ tube/box & $\begin{array}{c}\text { Flumetazone pivalate } 0.02 \% \\
\text { Salicylic acid } 3 \%\end{array}$ \\
\hline Locoid ointment $30 \mathrm{~g}$ tube/box & Hydrocortisone 17-Butyrate $0.1 \%$ \\
\hline M-Furo, ointment, $30 \mathrm{~g}$ tube/box & Mometasone furoate $0.1 \%$ \\
\hline Polimisin, ointment, $14 \mathrm{~g}$ tube/box & $\begin{array}{c}\text { Polymyxin B sulfate } 0.1 \% \\
\text { 0xytetracycline hydrochloride } 3 \%\end{array}$ \\
\hline Psovate, ointment, $50 \mathrm{~g}$ tube/box & Clobetazole propionate $0.05 \%$ \\
\hline Tetemex, ointment, $10 \mathrm{~g}$ tube/box & Diflukortolone valerate $0.1 \%$ \\
\hline Terramycin, ointment, $14.2 \mathrm{~g}$ tube/ointment & $\begin{array}{c}\text { Polymyxin B sulfate } 0.1 \% \\
\text { Oxytetracycline hydrochloride } 3 \%\end{array}$ \\
\hline
\end{tabular}

* Information was obtained from the RxMediaPharma® interactive drug information resource..$^{59}$

\section{Pomade}

Pomades are externally used semi-solid drug delivery systems prepared to be applied on the skin. There are $\mathrm{O} / \mathrm{W}$ emulsion types and they contain high oil (70\%). Therapeutically effective ointments have mildly softening and protective properties and additionally contain active ingredients with therapeutic effect. They have deep penetrating abilities. They do not clench the skin pores ${ }^{47}$ Corticosteroid or combination ointment formulations used in the treatment of SD are presented in Table 4. 
Table 4. Topical pomade preparations currently used in Turkey for SD.

\begin{tabular}{|c|c|}
\hline $\begin{array}{c}\text { The name of the preparation, } \\
\text { pharmaceutical form, amount }\end{array}$ & Active ingredients and ratio \\
\hline Beklazon, pomade, $30 \mathrm{~g}$ tube/box & Beclamethazone dipropionate $0.025 \%$ \\
\hline Diprolene, pomade, $15 \mathrm{~g}$ tube/box & Betamethasone dipropionate $0.05 \%$ \\
\hline Elocon, pomade, $30 \mathrm{~g}$ tube/box & Mometasone furoate $0.1 \%$ \\
\hline Hipokort, pomade, $30 \mathrm{~g}$ tube/box & Hydrocortisone acetate $0.5 \%$ \\
\hline Kenacort-A, pomade, $20 \mathrm{~g}$ tube/box & Triamnisolone acetonide $0.1 \%$ \\
\hline Prednol, pomade, $30 \mathrm{~g}$ tube/box & Prednasinolon $0.125 \%$ \\
\hline Prednol-A, pomade, $30 \mathrm{~g}$ tube/box & $\begin{array}{c}\text { Prednasinolon } 0.125 \% \\
\text { Iodochlorhydroscine } 3 \%\end{array}$ \\
\hline Seroderm, pomade, $30 \mathrm{~g}$ tube/box & \begin{tabular}{c} 
Betamethasone valerate $0.1 \%$ \\
\hline Thiocilline, pomade, $30 \mathrm{~g}$ tube/box
\end{tabular} \\
\hline Ultralan, pomade, $20 \mathrm{~g}$ tube/box & $\begin{array}{c}\text { Bacitrasyn IU/g } \\
\text { Neomycin sulphate } 0.5 \%\end{array}$ \\
\hline & $\begin{array}{c}\text { Flucortolon caproate } 0.25 \% \\
\text { Flucontholon } 0.25 \%\end{array}$ \\
\hline
\end{tabular}

* Information was obtained from the RxMediaPharma ${ }^{\circledR}$ interactive drug information resource. ${ }^{59}$

\section{Shampoo}

When shampoos are first discovered, shampoos are defined as effective cleansing agents for hair and scalp, but today this is not just what is expected from shampoo today. Although the functions of shampoos have become complicated in recent years, their main purpose is to clean the hair by removing sebum and foreign residues from the surface of the hair. ${ }^{48,49,50}$ Shampoos are also effective in the following cranial conditions; repair of alkaline neuralization ability, dryness, seborrhea, head skin infections (Malassezia spp., Propionibacterium spp.), the enzyme activation state on the head skin, arrhythmia of the head skin. ${ }^{48}$ Antifungal or combination shampoo formulations used in the treatment of SD are presented in Table 5 .

Table 5. Topical shampoo preparations currently used in Turkey for SD.59

\begin{tabular}{|c|c|}
\hline $\begin{array}{c}\text { The name of the preparation, } \\
\text { pharmaceutical form, amount }\end{array}$ & Active ingredients and ratio \\
\hline Fungoral, shampoo, $100 \mathrm{~mL}$ bottle/box & Ketoconazole $2 \%$ \\
\hline Ketoral, shampoo, $100 \mathrm{~mL}$ bottle/box & Ketoconazole $2 \%$ \\
\hline Konazol, shampoo, $100 \mathrm{~mL}$ bottle/box & Ketoconazole $2 \%$ \\
\hline Nizoral, shampoo, $60 \mathrm{~mL}$ bottle/box & Ketoconazole $2 \%$ \\
\hline Selsun blue, shampoo, $200 \mathrm{~mL}$ bottle/box & Selenium sulfide $1 \%$ \\
\hline T/GEL, shampoo $130 \mathrm{~mL} / 251 \mathrm{~mL}$ bottle/box & Coal tar $2 \%$ \\
\hline
\end{tabular}

* Information was obtained from the RxMediaPharma ${ }^{\circledR}$ interactive drug information resource. ${ }^{59}$ 


\section{Solution}

Solvents are a homogeneous mixture prepared by mixing two or more substances, that is, a mixture dissolved or dispersed all around the same. ${ }^{51}$ Solution formulations used in the treatment of SD are presented in Table 6.

Table 6. Topical solution preparations currently used in Turkey for SD.

\begin{tabular}{|c|c|}
\hline $\begin{array}{c}\text { The name of the preparation, } \\
\text { pharmaceutical form, amount }\end{array}$ & Active ingredients and ratio \\
\hline Dermatop, solution, $20 \mathrm{~mL}$ bottle/box & Prednikarbat $0.25 \%$ \\
\hline Ultralan, solution, $20 \mathrm{~mL}$ bottle/box & $\begin{array}{c}\text { Flucortolon pivalate } 0.5 \% \\
\text { Salicylic acid } \% 1\end{array}$ \\
\hline
\end{tabular}

* Information was obtained from the RxMediaPharma® interactive drug information resource. ${ }^{59}$

\section{Suspension}

Suspensions are heterogeneous systems containing two phases. The external phase, also referred to as the continuous phase or dispersion medium, is usually a liquid or semi-solid and the internal or dispersed phase is composed of particulate matter that is substantially insoluble in the external phase. Most drug suspensions consist of an aqueous dispersion medium, but in some cases organic or oily fluids are also used..$^{22}$ A suspension formulation used in the treatment of SD are presented in Table 7.

Table 7. Topical suspension preparation currently used in Turkey for SD.59

\begin{tabular}{|c|c|}
\hline $\begin{array}{c}\text { The name of the preparation, } \\
\text { pharmaceutical form, amount }\end{array}$ & Active ingredients and ratio \\
\hline Zetion, suspension, $100 \mathrm{~mL}$ bottle/box & Zinc pyrite $2 \%$ \\
\hline
\end{tabular}

* Information was obtained from the RxMediaPharma $®$ interactive drug information resource. ${ }^{59}$

\section{Gels}

The gel is a transparent or translucent semi-solid preparation in which one or more active substances are transported in suitable hydrophilic or hydrophobic bases. The gel may be clear or opaque, polar hydroalcoholic or nonpolar. Gels are either prepared by a special procedure required by a fusion process or by gelling agents, humectants and preservatives. ${ }^{53} \mathrm{~A}$ suspension formulation used in the treatment of SD are presented in Table 8.

Table 8. Topical gel preparation currently used in Turkey for SD. 59

\begin{tabular}{|c|c|}
\hline $\begin{array}{c}\text { The name of the preparation, } \\
\text { pharmaceutical form, amount }\end{array}$ & Active ingredients and ratio \\
\hline Pers-mant, gel, $30 \mathrm{~g}$ bottle/box & $\begin{array}{c}\text { Miconazole nitrate } 2 \% \\
\text { Aluminum hydroxychloride } 19 \%\end{array}$ \\
\hline
\end{tabular}

* Information was obtained from the RxMediaPharma® interactive drug information resource..$^{59}$ 


\section{New approaches}

Dandruff is a common haired skin problem of human beings, and most people suffer from this at some point in their lives. To prevent dandruff, pre-dandruff shampoos have become popular in recent years. However, in many cases, Malassezia furfur, which produces dandruff and is a cause of SD, develops resistance to widely used anti-dandruff drugs. As a result, a new class of pre-dandruff shampoos needs to be developed for dual purposes. In a study, it was mainly focused on a green nanoparticle-based green formulation of a pre-dandruff shampoo. In situ capped silver nanoparticles (Ag NPs) were prepared by green pathways using Acacia and Acacia + Aegle marmelos leaf extracts (LE) at sizes 40 and $13 \mathrm{~nm}$, respectively. Anti-fungal activity tests using a well diffusion technique showed that the $13 \mathrm{~nm}$ particles had better inhibitory activity compared to $40 \mathrm{~nm}$ particles, while the TTC (2,3,5-triphenyl-tetrazolium chloride) analysis method showed a minimum or threshold concentration of $0.054 \mathrm{mM}$ for both particle sizes used. The time-kill assay shows some synergism in the net antifungal effect of Acacia + LEs in aqueous media against M. furfur and in $13 \mathrm{~nm} \mathrm{Ag}$ NPs. However, the promising anti-Malassezia activity of $40 \mathrm{~nm}$ Ag NPs in Acacia medium and their superior suspension stability against microbial contamination means that they have potency as an active and simple antifungal shampoo formulation. ${ }^{54}$

In another study about silver nanoparticles, a detailed analysis of the treatment of hair-dermatitis infection using silver nanomaterials (AgNMs) is summarized and focuses on biocide activity due to manipulation of size, shape and structure. Monodisperse silver spherical nanoparticles (NPs) and nanorods (NRs) were synthesized chemically and characterized using analytical / spectroscopic techniques. Ag NMs showed more biocidal tendency and showed more inhibition zone compared to drugs in SD treatments, itraconazole and ketoconazole. Obtained $20 \mathrm{~nm}$ and $50 \mathrm{~nm}$ spherical NPs and $50 \mathrm{~nm}$ NRs showed concentration, size, and shape-dependent antifungal activity; $20 \mathrm{~nm}$ spherical NPs exhibited excellent potency. The minimum inhibitory concentration for $20 \mathrm{nM}$ was the lowest at $0.2 \mathrm{mg} / \mathrm{mL}$ compared to $0.3 \mathrm{mg} / \mathrm{mL}$ for NRs. The NMs with a $50 \mathrm{~nm}$ rod showed negligible redness, whereas the primary irritation index was 0.33 and 0.16 for $20 \mathrm{~nm}$ and $50 \mathrm{~nm}$ spherical NPs, respectively. An in vivo model for $M$. furfur infection was produced by passing fungi subcutaneously into rat skin. Again, $20 \mathrm{~nm}$ particles showed the best normalization of the skin after 10 days at regular dosing compared to larger and stick-shaped particles. The statistical clinical score was highest for Ag nanorods, followed by the animal treated with $50 \mathrm{nM}$ Ag NPs. $20 \mathrm{~nm}$ spherical particles exhibited the lowest score (o) as compared to the antifungal drugs as well as others. Biochemical analysis with anti- 
oxidant enzymatic activity control, tissue repair and enzymatic normalization and protein NP concentrations were shown. ${ }^{55}$

In another study about silver nanoparticles, nanoparticles (AgNP) were synthesized using Coriandrum sativum leaf extract. The physico-chemical properties of AgNPs have been analyzed by various analytical and spectroscopic methods. In addition, the in vitro anti-acne, anti-dandruff and anti-breast cancer efficacy of synthesized AgNPs were respectively assessed against cell lineage of Propionibacterium acnes MTCC 1951, Malassezia furfur MTCC 1374 and human breast adenocarcinoma (MCF-7), respectively. The flavonoids contained in the plant extract were responsible for AgNP synthesis. The size of the green synthesized nanoparticles was found to be $\sim 37 \mathrm{~nm}$. The BET (Brunauer-Emmett-Teller) analysis revealed that the surface area of synthesized AgNPs was $33.72 \mathrm{~m}^{2} \mathrm{~g}^{-1}$. It was found that the minimum inhibitory concentration (MIC) of AgNPs for $\mathrm{M}$. furfur, which is the causative agent of $\mathrm{P}$. acnes and dandruff, is 3.1 and $25 \mu \mathrm{g}$ mL-1, respectively. The half-maximal inhibitor concentration ( $\mathrm{IC}_{50}$ ) of $\mathrm{AgNPs}$ for MCF-7 cells was calculated to be $30.5 \mu \mathrm{g}$ mL-1and a complex inhibition at 100 $\mu \mathrm{g} \mathrm{mL}{ }^{-1}$ concentration was observed. Finally, the results can be interpreted as evidence that green-synthesized AgNPs using C. sativum have great potential in biomedical applications such as anti-acne, anti-dandruff, anti-SD and antibreast cancer therapy. ${ }^{56}$

Nanocrystals are nanoparticles composed of $100 \%$ drug without any matrix material, typically with a size range between 200 and 500 nm.57 In a study of nanocrystalline nanoparticles, ketoconazole nanoparticles were synthesized from ketoconazole powder in the market. Sonication has been preferred as the physical method used in the manufacture of ketoconazole nanoparticles. Particles analyzed by different analytical and spectroscopic methods reveal the formation of multi-parted ketoconazole nanoparticles of $51 \mathrm{~nm}$ particle size. In the antifungal activity study, it has been shown that synthesized ketoconazole nanoparticles exhibit significant activity against SD causes Malassezia furfur when compared to ketoconazole powder in the market. Furthermore, nanogel was prepared using ketoconazole nanoparticles with significant antimicrobial and antimalassezial activity. After systematic testing, the gel containing ketoconazole nanoparticles can be used as an anti-dandruff gel..$^{8}$

Another of the new therapeutic approaches is tacrolimus and pimecrolimus from the nonsteroidal macrolactamine immunomodulator group. These active ingredients have been tested on SD and found to be effective. These active ingredients act by inhibiting calcineurin. It is thought that these drugs may be useful in the treatment of SD because of the anti-inflammatory effects that they have. ${ }^{60,61,62}$ 
In vitro studies have suggested that tacrolimus may exhibit antifungal activity against $P$. ovale as another potential mechanism of action. ${ }^{25,60}$ These agents have a number of known side effects, including stinging, cough, fever, skin atrophy, burning, heading, upper respiratory infection and flu-like symptoms (among others). Not much is known about the long-term effects of calcineurin inhibitors. Those medications come with warnings that isolated cases of skin cancer and lymphoma have occurred. Never use these medications long-term under any circumstances. ${ }^{60}$

Another new approach to SD therapy is lithium compounds. Lithium succinate pomade with $8 \%$ lithium succinate and $0.05 \%$ zinc sulphate is available in some countries. ${ }^{63}$ Rapid improvement was achieved with lithium succinate pomade that administered twice a day in patients with AIDS and facial SD together. ${ }^{64}$ In another study, lithium succinate pomade has been shown to be effective in HIV negative SD cases. ${ }^{65}$ Lithium succinate pomade has a potent antiviral effect and was first developed as a possible treatment for oral and genital herpes. Treatment effect on SD was found by chance. This drug proved to be sufficient alone to control SD in all areas except the scalp ${ }^{64}$. In vitro studies have shown that lithium salts inhibit yeast proliferation. It is interpreted that this effect may be mainly related to the inhibition of free fatty acid production. Lithium salts also have an antiinflammatory effect by inhibiting arachidonic acid production. ${ }^{66}$ While some authors suggest that lithium succinate is effective against malassezia species in vitro, others have reported that they have anti-inflammatory effects rather than a specific antifungal agent. ${ }^{63,66}$

In another study aimed to investigate the efficacy of narrow-band ultraviolet (UV) B (TL-01) phototherapy as an alternative treatment for SD. Eighteen patients with severe disease were enrolled in an open prospective study. Treatment was given three times weekly until complete clearing or to a maximum of 8 weeks. A clinical score assessing erythema, scaling, infiltration and pruritus was performed at baseline and every 2 weeks thereafter. Additionally, the patients were asked to rate the intensity of pruritus on a visual analogue scale. After completion of the study the patients were followed up to determine the median time interval until recurrence. All patients responded favourably to treatment, with six showing complete clearance and 12 marked improvement. The median clinical score decreased from 7.5 (range $4 \pm 8$ ) at baseline to 0.5 (range $0 \pm 3$ ) after 8 weeks of treatment. The median pruritus score decreased from 4.5 (range $0 \pm 8$ ) at baseline to o (range $\mathrm{O} \pm 3$ ) at week 8 . Relapses occurred in all patients after a median of 21 days (range 12士40). No side-effects of treatment were observed except occasional episodes of a moderate erythemal response. As a conclusion 
this study, results demonstrate that narrow-band UVB is an effective alternative tool for the management of severe SD and should be considered for patients unresponsive to conventional treatments. ${ }^{67}$ The mode of action of narrow-band UVB in SD remains speculative yet presumably is related to its modulatory effect on inflammatory and immunological processes in the skin. In addition, a direct effect of UV irradiation on $P$. ovale leading to ultrastructural changes and growth inhibition has been reported.68,69

In one study, '1-24 dihydroxycholecalciferol' creams were applied twice a day for 4 weeks in patients with SD on their face and scalp. At the end of treatment all the lesions were seen to be regressed. No recurrence was observed at 2 months follow-up. ${ }^{70}$

\section{Role of Pharmacist}

Since SD is a condition that is visible, patients normally feel humiliated and may see themselves as distorted. Patients can profit significantly from the contribution of a pharmacist. The pharmacist ought to acquire a prescription history to ascertain the seriousness of the patient's manifestations, at that point offer guiding about the most proper over-the-counter regimen. Pharmacist ought to talk about the objectives of treatment, reasonable desires, length of treatment, suitable utilization of items, the significance of clinging to the regimen, and any conceivable unfriendly impacts. ${ }^{9}$

To diminish the danger of medication associations, the pharmacist ought to keep up refreshed prescription profiles for every patient, including the utilization of home grown items, nonprescription medications, and regular supplements. Also, the pharmacist should screen for attendant medications with a limited remedial file or medications that may collaborate with different medicines. The scope of treatments for SD can be overpowering to patients, however a pharmacist can help locate the fitting therapy or prompt them when discussion with a dermatologist is justified.

Initially it is important that patients get accurate information from pharmacists in skin diseases. In conclusion, although there are some identifiable opportunities to provide information to pharmacologic dermatology patients, it is important that they have adequate training.

Pharmacists must be fully trained and integrated to provide a comprehensive pharmaceutical care package for dermatology patients to require time.

"The task of the pharmacist is to give self-referral advice on dermatological conditions to people who have not seen a doctor, based on current information on 
over-the-counter (OTC) products. For example, health professionals recommend that people with eczema treat themselves by using a weak corticosteroid and emollient, and then refer people to a doctor if the eczema is severe or the cure fails.

The role of the pharmacist in therapeutic support seems unclear and probably not used enough. It has been suggested that the pharmacist is often the first and last provider they have encountered in the process up to the sum of the pills prescribed by the patient's skin treatment. In addition to the doctor and nurse, pharmacists may be more active following treatment in cooperation with other health professional. More drug treatment problems lead to the identification and resolution of a drug when it is examined by a pharmacist, which is only compared with patients who have regular contacts with their physician. This can reduce the direct cost of medicines and other health care use. Practical problems related to the application of topical preparations, lack of motivation and compliance, potential side effects and inadequate efficacy are problems that can be detected by the pharmacist.

The pharmacist's recommendations for infantile SD and adult SD cases should be different. In infants, SD is the primary treatment, to keep the skin dry and to relieve inflammation. Pharmacist should be recommended to families of infants suffered SD, such as diapers should not be used in hot weather, soap and puddle, or because they irritate eyes, should be avoided from tar preparations. Careful and moderate treatment regimens are recommended because the disease has a long course in adults. Pharmacists should be advised of the use of antiinflamatuaries, antimicrobial or antifungal agents, if necessary, and personal hygiene in adults exposed to SD. 64

Pharmacist has a great role in directing patients about antagonistic impacts, treatment results, consistence, and the fitting utilization of their recommended treatments of SD.

\section{CONCLUSION}

$\mathrm{SD}$ is a continuous disease spectrum that affects the seborrhoeic regions of the body. Various internal and environmental factors such as malassezia yeast, host epidermal conditions, sebaceous secretion, immune response and interactions between these factors may contribute to pathogenesis. Effective management of SD requires symptomatic relief, such as pruritus and overall hair and skin health, to help clear symptoms with antifungal and anti-inflammatory therapy, to help maintain remission. Studies in humans and animal models to investigate genetic and biochemical pathways will help identify new targets for the devel- 
opment of more effective treatment with fewer side effects and better manage these conditions. As it is understood from this review article; many active agents and traditional pharmaceutical formulations are still used in the treatment of SD. Besides, new pharmaceutical formulations and new agents to be used in SD treatment are being developed and their efficacy proved even if the market has not yet entered the market.

\section{REFERENCES}

1. Kacar, S.D.; Ozoguz, P. The Current Approach to Seborrheic Dermatitis. Kocatepe. Med. J. 2016, 17, 72-76.

2. Braun-Falco, O.; Plewig, G.; Wolff, H.H.; Burgdorf, W.H.C. Dermatology. Springer-Verlag Publisher: Berlin, Heidelberg, Germany, 1996; pp 105-106, 457-517.

3. Goodheart, H.P. Goodheart's Photoguide to Common Skin Disorders: Diagnosis and Management. Wolters Kluwer Health-Lippincott Williams\&Wilkins Publisher: Philadelphia, USA, 2008; pp77-82.

4. Johnson, B.A.; Nunley, J.R. Treatment of Seborrheic Dermatitis. Am. Fam. Physician. 2000, 61(9), 2703-2710.

5. Hughes, G.B.; Pensak, M.L. Clinical Otology. Thieme Publishers; Newyorkcity, USA, 2007, pp. 201-203.

6. Factor, S.A.; Weiner, W.J. Parkinson's Disease: Diagnosis and Clinical Management. Demos Medical Publishing; Newyorkcity, USA, 2oo8, pp. 46.

7. Del Rosso, J.Q. Adult Seborrheic Dermatitis: A Status Report on Practical Topical Management. J. Clin. Aesthet. Dermatol. 2011, 4(5), 32-38.

8. Borda, L.J.; Wikramanayake, T.C. Dandruff: A Comprehensive Review. J. Clin. Invest. Dermatol. 2015, 3(2), 1-22

9. Berk, T.; Scheinfeld, N. Seborrheic Dermatitis. Pharmacy and Therapeutics. 2010, 35(6), 348-352.

10. Harvey, L.L.; Nair, S.V.; Kass, I. Beclomethasone Dipropionate Aerosol in the Treatment of Steroid-Dependent Asthma. Chest. 1976, 3(70), 345-350.

11. Saraceno, R.; Gramicca, T.; Frascione, P.; Chimenti, S. Calcipotriene / Betamethasone in the Treatment of Psoriasis: A Review Article. Expert. Opin. Pharmacother. 2oo9, 10(14), 23572365 .

12. Iraji, F.; Banihashemi, S.H.; Faghihi, G.; Shahmoradi, Z.; Tajmirriahi, N.; Jazi, S.B. A Comparison of Betamethasone Valerate 0.1\% Cream Twice Daily Plus Oral Simvastatin Versus Betamethasone Valerate 0.1\% Cream Alone in the Treatment of Vitiligo Patients. Adv. Biomed. Res. 2017, 6, 34: doi:10.4103/2277-9175.203159.

13. Lowbury, E.J.L. Contamination of Cetrimide and Other Fluids with Pseudomonas pyocyanea. Br. J. Ind. Med. 1951, 1(8), 22-25.

14. Abidi, A.; Ahmad, F.; Singh, S.K.; Kumar, A. Study of reservoir effect of clobetasol propionate cream in an experimental animal model using histamine-induced wheal suppression test. Indian. J. Dermatol. 2010, 55(4), 329-333. 
15. Munro, D.D.; Wilson, L. Clobetasone butyrate, a new topical corticosteroid: clinical activity and effects on pituitary-adrenal axis function and model of epidermal atrophy. Br. Med.J. 1975, 13(3), 626-628.

16. Keeney, G.E.; Gray, M.P.; Morrison, A.K.; Levas, M.N.; Kessler, E.A.; Hill, G.D.; Gorelick, M.H.; Jackson, J.L. Dexamethasone for Acute Asthma Exacerbations in Children: A Meta-analysis. Pediatrics. 2014, 133(3), 493-499.

17. Samtani, M.N.; Jusko, W.J. Stability of dexamethasone sodium phosphate in rat plasma. Int. J. Pharm. 2005, 301, 262-266.

18. Kircik, L.H. Treatment of Scalp and Facial SDwith Desonide Hydrogel 0.05\%. J. Clin. Aesthet. Dermatol. 2009, 2(2), 32-36.

19. Baş, N.B.; Çetinkaya, S.; Ağdalığlu, S.Y.; Kendirci, H.N.P. [Iatrogenic cushing syndrome due to topical steroids]. Çocuk dergisi. 2010, $10(3), 152-155$.

20. Veraldi, S.; Persico, M.C.; Schianchi, R. Isoconazole Nitrate vs Isoconazole Nitrate and Diflucortolone Valerate in the Treatment of Tinea Inguinalis: Results of a Multicenter Retrospective Study. J. Drugs. Dermatol. 2012, 11(11), e70-e73.

21. Cudina, O.; Brboric, J.; Vujic, Z.; Radulovic, D.; Vladimirov, S. Determination of fluocortolone pivalate and fluocortolone hexanoate in suppositories using reverse-phase HP. Il Farmaco. 2000, $55(2), 125-127$.

22. Ultraproct ${ }^{\circledR}$. New Zealand Data Sheet. http://www.medsafe.govt.nz/profs/Datasheet/u/ ultraproctointsupp.pdf

23. Abdel-Aleem, E.A.; Hegazy, M.A.; Sayed, N.W.; Abdelkawy, M.; Abdelfatah, R.M. Novel spectrophotometric determination of flumethasone pivalate and clioquinol in their binary mixture and pharmaceutical formulation. Spectrochim. Acta. A. Mol. Biomol. Spectrosc. 2015, 136, 707-713.

24. Kanee, B. Clinical Studies with Topical Fluocinolone Acetonide in the Treatment of Various Dermatoses. Can. Med. Assoc. J. 1963, 88(20), 999-1003.

25. Bozkurt, N.M.; Başak, P.Y. [Seborrhoeic Dermatitis Treatment and New Treatment Approaches]. Türkderm. 2007, 41, 112-116.

26. Spencer, C.M.; Wiseman, L.R. Topical fluticasone propionate: a review of its pharmacological properties and therapeutic use in the treatment of dermatological disorders. BioDrugs. 1997, 7(4), 318-334.

27. Jerajani, H.R.; Kumar, A.S.; Kuruvila, M.; Nataraja, H.V.; Philip, M.; Pratap, D.V.S.; Sumathy T.K., Krishnankutty, B.; Dhawan, S.; Thomas, D. Efficacy and safety of topical halometasone in eczematous dermatoses in indian population: an open label, noncomparative study. Indian. J. Dermatol. 2011, 56(6), 652-656.

28. Torlak, I. A foamy pharmaceutical formulation used in dermatological diseases. Ogig Sağlik Ürünleri Ve Hizmetleri Sanayi Ticaret Limited Şirketi, Patent number: WO 2016159916 A1, 2016.

29. Abraham, A.; Roga, G. Topical Steroid-Damaged Skin. Indian. J. Dermatol. 2014, 59(5), 456-459.

30. Jackson, R. The Topical Use of Hydrocortisone and Hydrocortisone Acetate. Can. Med. Assoc. J. 1955, 72(12), 931-932. 
31. Brogden, R.N.; Pinder, R.M.; Sawyer, P.R.; Speight, T.M.; Avery, G.S. Hydrocortisone 17-Butyrate: A New Topical Corticosteroid Preliminary Report. Drugs. 1976, 12(4), 249-257.

32. Das, J.; Majumdar, M.; Chakraborty, U.; Majumdar, V.; Mazumdar, G.; Nath, J. Oral itraconazole for the treatment of severe seborrhoeic dermatitis. Indian. J. Dermatol. 2011, 56(5), 515-516.

33. Achour, S.; Abourazzak, S.; Mokhtari, A.; Soulaymani, A.; Soulaymani, R.; Hida, M. Juniper tar (cade oil) poisoning in new born after a cutaneous application. BMJ. Case. Reports. 2011, 2011: bcro720114427.

34. Nagpal, V.B.; Jain, V.K.; Aggarwal, K. Comparative study of oral and topical ketoconazole therapy in pityriasis versicolor. Indian. J. Dermatol. Venereol. Leprol. 2003, 69, 287-288.

35. Majid, I.; Masood, Q.; Hassan, I.; Khan, D.; Chisti, M. Chilhood vitiligo: response to methylprednisolone oral minipulse therapy and topiical fluticasone combination. Indian. J. Dermatol. 2009, 54(2), 124-127.

36. Molin, S.; Abeck, D.; Guilabert, A.; Bellosta, M. Mometasone Furoate: A Well-Established Topical Corticosteroid now with Improved Galenic Formulations. J. Clin. Exp. Dermatol. Res. 2013, $4,184$.

37. Gupta, M.; Mahajan, V.K.; Mehta, K.S.; Chauhan, P.S. Zinc Therapy in Dermatology: A Review. Derm. Res. Pract. 2014, 2014:709152, 1-11.

38. Gupta, A.K.; Chow, M. Prednicarbate (Dermatop®) Profile of a Corticosteroid. J. Cutan. Med. Surg. 2004, 8(4), 244-249.

39. Zanetti, F.R.; Fulco, E.A.M.; Chaves, F.R.P.; da Costa Pinto, A.P.; Arieta, C.E.L.; Lira, R.P.C. Effect of preoperative use of topical prednisolone acetate, ketorolac tromethamine, nepafenac and placebo, on the maintenance of intraoperative mydriasis during cataract surgery: A randomized trial. Indian. J. Ophthalmo. 2012, 6O(4), 277-281.

40. Hippalgaonkar, K.; Srirangam, R.; Avula, B.; Khan, I.A.; Majumdar, S. Interaction between Topically and Systemically Coadministered P-Glycoprotein Substrates/Inhibitors: Effect on Vitreal Kinetics. Drug. Metab. Dispos. 2010, 38(10), 1790-1797.

41. Gary, G. Optimizing Treatment Approaches in Seborrheic Dermatitis. J. Clin. Aesthet. Dermatol. 2013, 6(2), 44-49.

42. Madan, R.K.; Levitt, J. A review of toxicity from topical salicylic acid preparations. J. Am. Acad. Dermatol. 2014, 70(4), 788-792.

43. Pando, D.; Caddeo, C.; Manconi, M.; Fadda, A.M.; Pazos, C. Nanodesign of olein vesicles for the topical delivery of the antioxidant resveratrol. J. Pharm. Pharmacol. 2013, 65,1158-1167.

44. Garg, T.; Rath, G.; Goyal, A.K. Comprehensive review on additives of topical dosage forms for drug delivery. Drug. Deliv. 2015, 22(8), 969-987.

45. Crommelin, D.J.; Storm, G.; Jiskoot, W.; Stenekes, R.; Mastrobattista, E.; Hennink, W.E. Nanotechnological approaches for the delivery of macromolecules. J. Control. Release. $\mathbf{2 0 0 3 ,}$ $87,81-88$.

46. Weiss, S.C. Conventional topical delivery systems. Dermatologic. Therapy. 2011, 24, 471476 .

47. Değim, T. [Skin absorption and semi-solid preparations applied to the skin (Chapter 18)], 
In Modern Farmasötik Teknoloji. Türk Eczacıları Birliği Eczacılık akademisi Yayınları; Ankara, Turkey, 2007; pp 337-364.

48. Trüeb, R.M. Shampoos: Ingredients, Efficacy and Adverse Effects. Journal Der Deutschen Dermatologische Gesellschaft. 2007, 5, 356-365.

49. Mottram, F.J.; Lees, C.E.; Poucher's Perfumes, Cosmetics and Soaps. 10th ed. Kluwer Academic Publishers: Great Britain, UK: 20oo, pp. 289-306.

50. Yener, G. Saç ve Saça Uygulanan Kozmetik Ürünler. Ed. Yazan Y. In Kozmetik Bilimi. Nobel Tip Kitap Evleri: İstanbul, Turkey, 2010. pp 178-192

51. Değim Z. [Solutions (Chapter 12)] Modern Farmasötik Teknoloji. Türk Eczacıları Birliği Eczacllık akademisi Yayınları: Ankara, Turkey: 2007, pp 228-242.

52. Nutan, M.T.H.; Reddy, I.K. Chapter 2 General Principles of Suspensions. In: Pharmaceutical Suspensions: From Formulation Development to Manufacturing, DOI 10.1007/978-1-44191087-5_2, pp 39-65

53. Garg, T.; Singh, S.; Goyal, A.K. Stimuli-sensitive hydrogels: an excellent carrier for drug and cell delivery. Crit. Rev. Ther. Drug. Carrier. Syst. 2013, 30, 369-409.

54. Rao, K.J.; Paria, S. Anti-Malassezia furfur activity of natural surfactant mediated in situ silver nanoparticles for a better antidandruff shampoo formulation. R.S.C. Adv. 2016, 6,1106411069.

55. Anwar, M.; Yadav, D.; Jain, S.; Kapoor, S.; Rastogi, S.; Arora, I.; Samim, M. Size- and shape-dependent clinical and mycological effcacy of silver nanoparticles on dandruff. Int. $J$. Nanomedicine. 2016, 11, 147-161.

56. Sathishkumar, P.; Preethi, J.; Vijayan, R.; Mohd Yusoff, A.R.; Ameen, F.; Suresh, S.; Balagurunathan, R.; Palvannan, T. Anti-acne, anti-dandruff and anti-breast cancer efficacy of green synthesised silver nanoparticles using Coriandrum sativum leaf extract. J. Photochem. Photobiol. B. 2016, 163, 69-76.

57. Attama, A.A.; Reginald-Opara, J.N.; Uronnachi, E.M.; Onuigbo, E.B. Chapter 25-Nanomedicines for the Eye: Current Status and Future Development. In: Nanoscience in Dermatology https://doi.org/10.1016/B978-0-12-802926-8.00025-2. UK; Academis Press UK, 2016, pp 323-326.

58. Paralıkar, P. Fabrication of ketoconazole nanoparticles and their activity against Malassezia furfur. Nusantara. Bioscience. 2015, 7(1), 43-47.

59. RxMediaPharma $®$ interaktif ilaç bilgi kaynağı

6o. Braza, T.J.; DiCarlo, J.B.; Soon, S.L.; McCall, C.O. Tacrolimus o.1\% ointment for seborrheic dermatitis: an open-label pilot study. Br. J. Dermatol. 2003, 148, 1242-4.

61. Crutchfield, C.E. Pimecrolimus: a new treatment for seborrheic dermatitis. Cutis. 2oo2, 70, 207-8.

62. Brownell, I., Quan, L.T.; Hsu, S. Topical pimecrolimus in the treatment of seborrheic dermatitis. Dermatol. Online. J. 2003, 9, 13.

63. Gupta, A.K.; Bluhm, R. Seborrheic dermatitis. J. Eur. Acad. Dermatol. Venereol. 2004, $18,13-26$.

64. Inalöz, H.S.; Kırtak, N. The pathogenesis and treatment of seborrheic dermatitis. T. Klin. J. 
Med. Sci. 2002, 22, 239-244.

65. Langtry, J.A.A.; Rowland Payne, C.M.E.; Staughton, R.C.D.; Stewart, J.C.M.; Horrobin, D.F. Topical lithium succinate ointment (Efalith) in the treatment of AIDS-related seborrheic dermatitis. Clin. Exp. Dermatol. 1997, 22, 216-219.

66. Dreno, B.; Chosidow, O.; Revuz, J.; Moyse, D. Lithium gluconate 8\% vs ketoconazole 2\% in the treatment of seborrheic dermatitis: a multicentre, randomized study. Br. J. Dermatol. 2003, 148, 1230-1236.

67. Pirkhammer, D.; Seeber, A.; Hönigsmann, H.; Tanew, A. Narrow-band ultraviolet B (TLo1) phototherapy is an effective and safe treatment option for patients with severe seborrheic dermatitis. Br. J. Dermatol. 200o, 143, 964-968.

68. Duthie, M.S.; Kimber, I.; Norval, M. The effects of ultraviolet radiation on the human immune system. Br. J. Dermatol. 1999, 140, 995-1009.

69. Wikler, J.R.; Janssen, N.; Bruynzeel, D.P.; Nieboer, C. The effect of UV-light on Pityrosporum yeasts: ultrastructural changes and inhibi- tion of growth. Acta. Derm. Venereol. (Stockh). 1990, 70, 69-71.

70. Kiremitçi, Ü.; Topçu, E.; Serdaroğlu, S. [Seborrheic dermatitis treatment]. Dermatose. 2004, 2, 146-50. 